\title{
Research on Urban Landscape Design based on Spatial Color \\ Qiu Tongwen
} College of Art and Design,Shandong University of Science and Technology, Qingdao, Shandong,
China

8108250@163.com

Keywords: Urban Road, Green Land Landscape, Color.

\begin{abstract}
Use the different response and understanding of the passers-by treating the colors and the regulating role of colors in the environment of urban road green land landscape to make the research thoroughly on the color collocation of the road green land landscape. The author makes every effort to achieve a change in unity about the color utilization of road green land landscape so as to enrich the urban road green land landscape.
\end{abstract}

\section{The Color Composition, Function and Effect of the Urban Road Green Land Space}

The impression for a city always starts from the "look", and the color is the first element of vision. so talking about the urban road green land landscape is also inseparable from the research on the color problem. In the modern society with the rapid development of science and technology the urban color presents the multi-coloring, and at the same time it also puts forward the thinking for us. The use of artificial colors has been far more than the material color, what's more, it presents a very strongly trend to contend with natural colors. Reasonably make the natural and artificial color in urban road landscape be used in the design of road green land organically. It is also an effective method to create a urban scenery line with character and charm.

The living space of city is relatively narrow, and the pace of life is fast, and the work pressure is big, so the use of urban color should be very exquisite, one can' $t$ follow one' $s$ inclinations. The color selection should not only reflect the meaning which the environment itself wants to convey, but also need to consider the feeling of road user treating the road color. That is the intangible and abstract spirit effect of the color in human life. It is one of external factor which can arouse the greatest change of human emotion and mood.

In the design, color can be considered as a kind of subjective language to use. Their significance is related to emotions and associations. And the national tradition and culture also plays an important role. At the same time, due to the different environment and association a kind of color may have several different kinds of effects. Different color environment will have corresponding different effect to human's mood. Some American scientists once made the college students who receive the tests stay in the empty room with the same color whose four walls are all white, as a result, after three days someone got the memory loss and mental decline and after five days someone got neurological disorder and other phenomena of mechanism disorder. Since urban road landscape color has the effect on the mental state and emotion of road user, people have begun to realize that the irrational use of color is actually a kind of disaster. Color pollution and flood have gradually aroused people's concern. According to the statistics data, it shows that in recent years disputes caused by urban color have presented a growing trend in Japan. In 1976, only six complaints about color are put forward. And by 1993, the number has become 16. Among them, a "color disturbance" about the citizens occurs in Tokyo, Japan. Because the citizens have witnessed the flowing gorgeous buses and taxis with high chroma, the neon lights with ever-changing colors, colorful commercial advertisements, roadside gleaming glass mirror, glass curtain wall and the buildings decorated by ceramic tiles with all kinds of colors and other things for a long time, they feel dizzy and restless. Thus, they express their strong displeasure for this kind of disturbance caused by the urban color. So it forces Tokyo municipal authorities to have no choice but to try to correct the color deviation so as to eliminate the emotions of restlessness and irritability in the mind of citizens. 
In the color composition of urban road green land landscape, keynote color, primary color, broken color and accent color do not exist in isolation. Its classification is also not to emphasize their own existence, but to emphasize the relationship relying on each other between several big categories and between them and the main color of city. The keynote color, primary color, broken color and accent color only take paying attention to the overall quality of the road landscape color as the principle, and get reasonable collocation so as to make whole color be harmonious and vivid. Walking in the streets of Paris, whether the color of the building, or footway pavement, we all use gray series. Even the colors of cover and neon are also white for the majority. The woman who wears a dark red dress and wears a dark red hat is walking in the street which takes this kind of tone as the background will be extraordinarily beautiful. Orange telephone booths or newsstands also will become a beautiful scenery.

\section{The Use of the Individual Reflection about Integral Color in Urban Road Green Land Space}

The Reconstruction of Main Color. Urban road green land landscape color is also one of the factors which reflect urban road style and features. As each city road moves forward, because of its social and natural conditions it forms the unique color environment which is also favored by local road users. While the personality reflection of integral color in urban road green land space takes the vegetation coverage of roads, squares and parking lots as the main factor. It is also the important reflection of road green land main color. The reconstruction of the main color about urban road green land space must first confirm the main color of the plant species. Many countries all consider the confirmation of the urban road main color tree species as an important content in the planning of road color. The thing that we need to stress is that the confirmation of the urban road main color tree species is not an easy thing. It needs us to fully understand the history and culture, local conditions and customs of the city and the local people's preferences. Usually we choose the local tree species in the urban area. Different functional areas have different requirements for the shape, size and density and others of tree species.

These all require a lot of practice investigation and scientific research, induction and summary to decide. After we confirm the main color tree species, related laws and regulations must be established.

After establishing the mass-tone attune tree species, laws and regulations must be established.Any building, rebuilding and expansion projects of city will strive to coordinated with the mass-tone attune of the city. Any newly-built, rebuilt and expanded construction projects in the city will strive to be coordinated with the main color of the city.

The color of greening plants on road is very rich and colorful. It can increase many colors in the street. Using the color change of plants' unique flowers, leaves and branches can bring unexpected effect for the characterization of city streets, especially some plants with local representative.

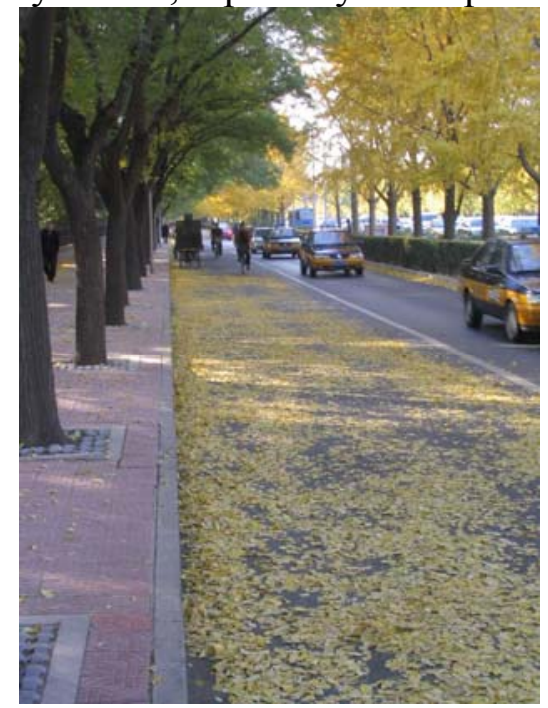

Fig. 1 The street of Dandong City---- Golden Ginkgo Tree 
While in Dandong, people like ginkgo tree. (Seen in Figure 1) Ginkgo tree not only has very high ornamental value for its handsome appearance, and tall and straight shape, and exquisite and peculiar leaves. What's more, it has strong adaptability and large medicinal efficacy, and its economic value is also very considerable. A poet in Song dynasty, Su Dongpo wrote in his poem:

"The peaks and mountains all around, and delicate and picturesque things are full of our eyes. A giant tree erects , the doodles with noughts and crosses can form an article." In big streets and small alleys, and parks of Dandong city area, there are quite a number of ginkgo trees with the age of $300-500$. The downtown main street, is almost covered with the ginkgo trees which are more than one hundred years old. A golden scenery is loved and favored by the local citizens.

Striving for a Change in the Unity. Urban road green land landscape color is a significant symbol for constituting the social civilization degree. Especially the green corridor formed by the natural vegetation color of the road green belt (including center island green land), square green land and of parking lots green land reflects the needs of humanity. It can make up the indifferent feeling which the high-tech development brings to the modern city life. It enables to achieve a harmonious and tacit among people, nature and society. The practical application of color in the urban road green land landscape design is to create the color beauty of urban road landscape.

The pursuing goal of color application in urban road green land landscape is "Striving for a change in the unity". Unity is the primary, and it is also inevitable. It refers to the essence of urban road green land, and other color of each space must obey and unify the green tone of whole road. Change is secondary, but it is necessary. It relies on loosening the color control of subsidiary scenery with road green land, such as the billboards on both sides of the road, square pavement, the buildings around the parking lot and others, and the meticulous design of other road green land landscape elements to achieve this goal. Ideal result of color application is to make bright green main color of road green land be maintained and lasted, and at the same time enrich its overall features of color composition so as to avoid causing the color convergence with the roads of other city.(Figure 2)

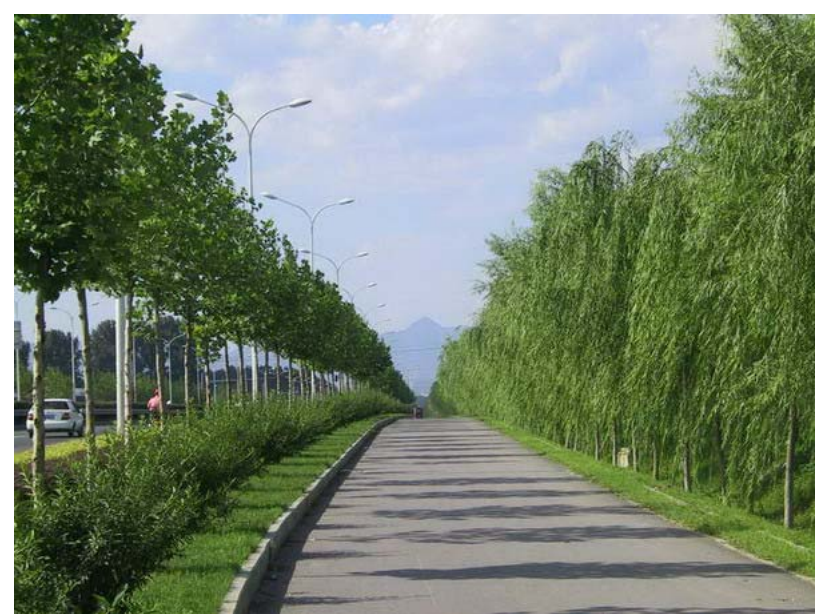

Fig. 2 The Daffodils divided lane in the streets of Netherlands

\section{The Color Selection of Public Facilities in Urban Road Green Land}

Because it has close relationship with human, we can't ignore the important effect of the color about public environment facilities which can be considered as the embellishment color in shaping the color individuality of urban road green land landscape. The color of public station, the color of the phone booth, the color of trash can, the color of resting chair and the color of the roadside railing, the color of the guideboard and so on are all the objects which need to be planned. It not only reflects the functional requirements which are easy to catch people's eyes and recognize but also forms the features which this city has rather than other city has.(Fig. 3) 


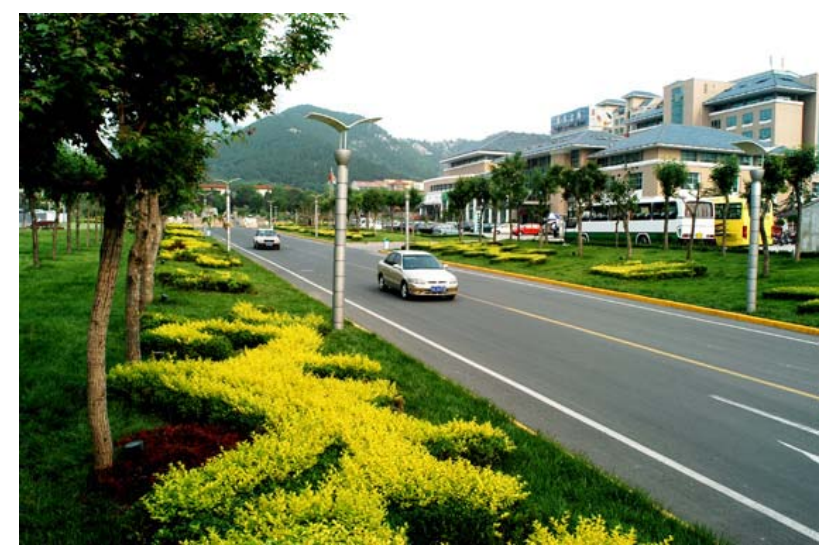

Fig. 3 The color application of public facilities in road green land

Light poles, seats, and dustbins all used dark reddish purple color in Corso pedestrian street in Sydney, Australia. The color is uniform, and it is decorated combining with the paved color. The buildings along the street keep old-style building facade and scale without mass-demolishing and big change, therefore very continuous interfaces on both sides show the diversity fully and even the contradiction and conflict to some degree.

However, because of the the unity of color, pattern, texture, and street furniture of the whole street ground, the leading role of outstanding image about the strong voice which constitutes the spatial ground and the date palms which are full of regional features, it makes people feel the space harmonious beauty and diversity with the enrichment of the whole street. The garbage bins on the section of Shanghai Huaihai road use all kinds of full and sedate red, yellow, black and other colors to match so as to make it seem fresh and special. The garbage bins in the environment of outside the Sydney opera house, not only use the shape which is echoed by the buildings in shape, but also reflect the light colors which are harmonious with "sea and groups of sails". These examples give us such inspiration that the facilities in the public environment are not necessary to form with bright colors. Using some colors with low chroma and taller colour lightness can also achieve impressive and harmonious effect. In some urban road green land environment of our country, the color of many public facilities is too bright, and the telephone booth is the collocation of red and green, and the platform is the collocation of red and green. These are echoed by the colorful billboards in the background but the identification is very poor. But it is not to say that we will put an end to use bright colors in the urban road green land environment but we will emphasize the reasonable use of color. We will strictly control to use the colors which will do damage to the image of the urban green land and cause the visual pollution.

\section{References}

[1] D.N. Xiao, X.Z. Li and so on. Landscape Ecology. Science Press. 2003. 67-84.

[2] T.S. Li. Urban Landscape Ecological Construction ----Take Shenyang City as an Example. Urban Environment \& Urban Ecology, 1996, 6 (3):34-37.

[3] F.C. Zeng, C.X. Run. Several Viewpoints of Building Green Channel Engineering. Henan Forestry, 1998 (3).34-35.

[4] Shi Shuwen compiled. The Color Design of Building Environment:China Building Industry Press, 1991. 7

[5] L. Lin. The Photography of Color.Henan Science and Technology Press, 2002. 